\title{
COVID-19: Impactos ocasionados na saúde mental em estudantes do ensino superior
}

\section{brasileiro}

COVII-19: Impacts on mental health in Brazilian higher education students

COVID-19: Impactos en la salud mental en estudiantes brasileños de educación superior

Recebido: 20/06/2021 | Revisado: 25/06/2021 | Aceito: 10/07/2021 | Publicado: 20/07/2021

Julietty Pinto Diniz Guimarães

ORCID: https://orcid.org/0000-0003-1748-7102

Faculdade Guaraí, Brasil

E-mail: julietypinto_diniz@hotmail.com

Fabiana Alves Rodrigues

ORCID: https://orcid.org/0000-0002-5307-0905 Faculdade Guaraí, Brasil

E-mail: enfermagem.fabyana@gmail.com

Adriana Keila Dias

ORCID: https://orcid.org/0000-0003-1291-5593

Faculdade Guaraí, Brasil

E-mail: adrianakeiladias@hitmail.com

Ana Paula Martins Guimarães

ORCID: https://orcid.org/0000-0002-0926-7962

Faculdade Guaraí, Brasil

E-mail: biologa.apmg@gmail.com

Giullia Bianca Ferraciolli do Couto

ORCID: https://orcid.org/0000-0002-9768-778X

Faculdade Guaraí, Brasil

E-mail: giulliabianca@ hotmail.com

Reobbe Aguiar Pereira

ORCID: https://orcid.org/0000-0003-2578-2611

Faculdade Guaraí, Brasil

E-mail: enfreobbe@gmail.com

Glaucya Wanderley Santos Markus

ORCID: https://orcid.org/0000-0001-8916-1086

Faculdade Guaraí, Brasi

E-mail: glaucyamarkus@outlook.com

Juliane Marcelino dos Santos

ORCID: https://orcid.org/0000-0003-4960-537X

Faculdade Guaraí, Brasil

E-mail: julianemarcelino@hotmail.com

\begin{abstract}
Resumo
A COVID-19 é uma doença causada por um novo patógeno viral denominado Sars-Cov-2. Esta doença apresenta sintomas que variam em uma escala global de: leve, moderada, grave, muito grave e óbito a depender da resposta do organismo do paciente. Atualmente, este patógeno é responsável por causar uma das maiores pandemias vivenciadas pelo ser humano em todo o mundo. Além dos problemas de saúde ocasionados pela doença, a humanidade também está lidando com os problemas de saúde considerados secundários, como por exemplo, o adoecimento mental, especialmente dos estudantes de ensino superior brasileiro. Considerando estas informações, o presente trabalho tem por objetivo apresentar um documento oriundo de uma revisão da literatura sobre os impactos causados pela pandemia do Sars-Cov2 na saúde mental da população de acadêmicos brasileiros. O procedimento metodológico do trabalho consiste em uma revisão da literatura, de caráter qualitativo, descritivo e exploratório, realizada em periódicos de artigos científicos, em repositórios de universidades e em sites governamentais. No transcorrer da pesquisa, observou-se que, os maiores transtornos mentais desenvolvidos por estas pessoas no período pandêmico foram: depressão, estresse, medo, ansiedade, insônia, agressividade, irritabilidade e angústia. Desta forma, conclui-se que, uma das estratégias que poderiam minimizar os efeitos da pandemia nesta população seria a disponibilidade de tratamento psicológico online gratuito disponibilizado pelo poder público e/ou pelas instituições de ensino superior em forma de projetos de extensão desenvolvidos por acadêmicos dos cursos da saúde.
\end{abstract}

Palavras-chave: Isolamento social; Aulas remotas; Ansiedade; Depressão; Estresse Fisiológico. 


\begin{abstract}
COVID-19 is a disease caused by a new viral pathogen called Sars-Cov-2. This disease presents symptoms that vary on a global scale of: mild, moderate, severe, very severe and death depending on the response of the patient's organism. Currently, this pathogen is responsible for causing one of the largest human-experienced plagues worldwide. In addition to the health problems caused by the disease, humanity is also dealing with health problems considered secondary, such as mental illness, especially of Brazilian higher education students. Considering this information, the present work aims to present a document from a review of the literature on the impacts caused by the Sars-cov- 2 pandemic on the mental health of the population of Brazilian academics. The methodological procedure of the work consists of a review of the literature, of qualitative, descriptive and exploratory character, carried out in journals of scientific articles, in repositories of universities and in government websites. During the research, it was observed that the greatest mental disorders developed by these people in the pandemic period were: depression, stress, fear, anxiety, insomnia, aggressiveness, irritability and anguish. Thus, it is concluded that one of the strategies that could minimize the effects of the pandemic in this population would be the availability of free online psychological treatment provided by the government and/or higher education institutions in the form of extension projects developed by academics of health courses.
\end{abstract}

Keywords: Social isolation; Remote classes; Anxiety; Depression; Physiological Stress.

\begin{abstract}
Resumen
COVID-19 es una enfermedad causada por un nuevo patógeno viral llamado Sars-Cov-2. Esta enfermedad presenta síntomas que varían a escala global desde: leve, moderado, severo, muy severo y muerte dependiendo de la respuesta del organismo del paciente. Actualmente, este patógeno es el responsable de provocar una de las mayores pandemias que experimenta el ser humano en el mundo. Además de los problemas de salud causados por la enfermedad, la humanidad también está lidiando con problemas de salud considerados secundarios, como las enfermedades mentales, especialmente entre los estudiantes brasileños de educación superior. Teniendo en cuenta esta información, este trabajo tiene como objetivo presentar un documento de revisión de la literatura sobre los impactos causados por la pandemia Sars-cov-2 en la salud mental de la población académica brasileña. El procedimiento metodológico del trabajo consiste en una revisión de la literatura, cualitativa, descriptiva y exploratoria, realizada en revistas de artículos científicos, repositorios universitarios y sitios web gubernamentales. En el transcurso de la investigación se observó que los mayores trastornos mentales desarrollados por estas personas en el período pandémico fueron: depresión, estrés, miedo, ansiedad, insomnio, agresividad, irritabilidad y angustia. Así, se concluye que una de las estrategias que podría minimizar los efectos de la pandemia en esta población sería la disponibilidad de tratamiento psicológico online gratuito brindado por el gobierno y/o instituciones de educación superior en forma de proyectos de extensión desarrollados por académicos de los cursos de salud.
\end{abstract}

Palabras clave: Aislamiento social; Clases remotas; Ansiedad; Depresión; Estrés fisiológico.

\title{
1. Introdução
}

Inúmeras patologias acometem o ser humano desde os primeiros relatos de sua existência na Terra. Algumas destas, apresentavam abrangência global e alcançavam inúmeras localidades do planeta de forma abrupta, na maioria das vezes com alta habilidade de transmissão e infecção.

Segundo Júnior (2020), desde a chegada de Colombo as américas, é possível perceber o surgimento de novas doenças, as quais eram transmitidas pelos viajantes por onde quer que passassem, e tais doenças sem estudos e sem cura, eram repassadas de pessoa a pessoa causando milhares de mortes. A transmissão de doenças de maneira crescente afetando vários países pode ser denominada como uma pandemia, tendo em vista a dificuldade de controlar o surto existente em determinado local e a sucessiva propagação (Martins et al., 2016), do agente patogênico.

Portanto, inúmeras patologias assolaram diferentes nações em todo o mundo até que pesquisadores e a ciência conseguissem produzir uma cura ou uma forma de prevenção para evitar a contaminação de pessoas em larga escala. Contudo, alguns problemas de saúde relacionadas a infecção por patógenos estão registradas na história devido ao impacto social e, as inúmeras mortes causadas.

Nas últimas décadas foi possível observar doenças que foram capazes de gerar pandemias, como é o caso da Gripe Espanhola ocorrida no final da Primeira Guerra Mundial, a qual teve três momentos, com 2 anos de durante (1918 a 1920). Diante deste contexto, inúmeros autores enfatizam que, o advento da Primeira Guerra Mundial intensificou o processo de disseminação do patógeno causador da doença, ocasionando assim, um número elevado de morte pela doença, devido as 
condições de convivência diário ao qual milhares de soldados se encontravam, debilitados e expostos (Martins et al., 2016 \& Ribeiro et al., 2020).

Atualmente, o mundo encontra-se mais uma vez acometido por uma pandemia, agora causada por um novo tipo de Coronavírus (Sars-Cov-2), responsável pela recente doença “COVID-19”. Alguns autores comparam a pandemia da Gripe Espanhola com a COVID-19, devido as características similares relacionadas aos sintomas, a taxa de transmissão e mortalidade.

Devido estas características e a necessidade do distanciamento social para a contenção da transmissão da doença, a COVID-19 ocasionou expressivas mudanças na sociedade contemporânea. Estas mudanças podem ser vistas tanto no modo de se relacionar das pessoas, como na forma de resolver problemas, propor ações relacionas ao cotidiano das pessoas, sendo necessário uma readaptação da rotina individual e coletiva. Estas readaptações ocorreram em várias áreas de abrangência do ser humano, especialmente, na educacional, pois, professores e alunos foram forçados a lidar com um novo cenário relacionado ao processo ensino-aprendizagem.

Estas mudanças foram sentidas em todos os níveis de escolaridade, no entanto, o nível mais impacto foi o técnico, tecnólogo e superior, considerando as restrições implantadas devido a necessidade de contenção da doença por meio do distanciamento social. Estas restrições reinventou o processo educativo por meio da educação à distância conhecido como EAD e/ou o ensino remoto. Desta forma, as faculdades, institutos e universidades precisaram aderir o uso de Tecnologias da Informação e Comunicação (TIC's), como instrumentos para ministrar suas aulas.

De acordo com Silva et al. (2020) em cursos catalogados na área da saúde, estes recursos tecnológicos só acomodariam $20 \%$ da carga horária total, considerando que, mais de $50 \%$ da carga horária na maioria dos cursos e em específico em cursos da saúde, é desenvolvida através de aulas práticas (Ribeiro et al., 2020).

Neste contexto, alguns autores observaram que, o ensino remoto ou a distância, associados ao isolamento social e inúmeros outros fatores, estão impactando negativamente a saúde mental dos estudantes brasileiros, especialmente aqueles matriculados em cursos de ensino superior. De acordo com Schmidt et al., (2020), as medidas de contenção a pandemia da COVID-19 podem ser consideradas fatores de risco a saúde mental da população, e isto, com base nos sintomas relacionados ao estresse pós-traumático, confusão e raiva.

Considerando a relevância social do assunto diante do quadro pandêmico ao qual vivenciamos atualmente, faz-se necessário intensificar os estudos relacionado aos efeitos da COVID-19 na saúde mental dos discentes universitários de forma geral. Contudo, o objetivo do presente trabalho é apresentar um documento oriundo de uma revisão da literatura sobre os impactos causados pela pandemia do Sars-Cov-2 na saúde mental da população de acadêmicos brasileiros.

\section{Material e Métodos}

O presente trabalho trata-se de uma revisão da literatura de caráter qualitativo, descritivo e exploratório, seguindo as recomendações de Lakatus et al., (2003) \& Venceslau et al., (2017), com adaptações. Por tanto, esta revisão foi realizada utilizando-se como base de dados artigos científicos, dissertações de mestrado, teses de doutorado e documentos. As buscas por estes arquivos foram realizadas em plataformas de pesquisa cientifica como: Google Acadêmico, Scielo, periódicos de revistas científicas e repositórios de universidades.

O caráter exploratório-descritivo, conforme Pereira et al., (2018), refere à pesquisa que tem como ambiente natural levantamento bibliográfico, com uma análise minuciosa e descritiva do objeto do estudo.

Para realizar a busca dos trabalhos foram utilizadas as seguintes palavras-chave: COVID -19; Sars-Cov-2; Saúde mental de acadêmicos na pandemia; distúrbios mentais causados pelo isolamento social; depressão e COVID -19; histórico do SarsCov-2. 


\section{Resultados e Discussão}

\section{Coronavírus: Histórico, conceitos e definições}

A evolução tanto tecnológica quanto cientifica traçaram novos caminhos para descobertas inimagináveis para o ser humano, aos quais, anteriormente, eram de acesso restrito apenas para a classe de estudiosos e cientistas. No entanto, com o passar do tempo, todo este conhecimento se tornou a partir das revoluções, mais acessível à população.

No entanto, apesar de existir um novo formato de ciência, assim como, de tecnologias, essas não puderam evitar que doenças e pragas assolassem a sociedade ao passar dos anos (Venceslau et al., 2017). Desde o século VI, inúmeras doenças geraram caos na sociedade, tais como a Praga de Justiniano, a Peste Negra, a Tuberculose Respiratória e a Gripe Espanhola, a qual surgiu já no século XX (Venceslau et al., 2017 \& Senhoras, 2020).

Diante dos avanços e descobertas realizadas a partir do século XX, que propiciaram a criação de vacinas e medicamentos, a sociedade preocupou-se e uniu forças para combater os males patológicos, com a finalidade de diminuir a difusão e mortalidade global, por meio da consolidação da Organização Mundial da Saúde (OMS), a qual se tornou o epicentro de um sistema político de saúde (Homma et al., 2011). Todavia, apesar de inúmeros avanços, o futuro ainda é incerto e imprevisível, pois, não há como prevenir novas patologias que são desconhecidas (Senhoras, 2020).

Diante desta perspectiva, o ano de 2019 foi marcado pela descoberta de uma nova forma viral, modificada, responsável por inúmeros eventos de infecções respiratórias em seres humanos. Diante de estudos específicos, este patógeno foi identificado como pertencente ao grupo dos Coronavírus, sendo um patógeno que se enquadra na ordem Nidovirales, da família Coronaviridae (Oliveira, 2020), subfamília Orthocoronaviridae e Gênero Betacoronavírus ( $\beta$-COV), como o MERS- Cov e SARS- Cov (Wang et al., 2020).

Estudos realizados em 1965, traçou por meio observações microscópicas o perfil morfológico dos vírus pertencentes a esta família, que apresenta estrutura viral similar a uma coroa (Brasil, 2020), ao qual originou o nome da família (Coronavírus).

Estes vírus são considerados pela ciência como os maiores retrovírus (compostos exclusivamente de ácido ribonucleico de fita simples - RNA). Apresentam morfologia esférica, dotados de uma cápsula proteica (capsídeo) envolvida por uma camada de proteínas (S). Estas proteínas se apresentam em forma de espículas e, dão origem a uma estrutura com morfologia similar a uma coroa, que determina a habilidade do vírus em interagir com a membrana plasmática das células do hospedeiro (tropismo viral) (Souza et al., 2021).

Os agentes patogênicos inseridos na família do Coronavírus são responsáveis por causar infecções moderadas, especialmente no aparelho respiratório superior de mamíferos, inclusive do ser humano. No entanto, devido a incontáveis interações moleculares entre o vírus e seus hospedeiros, este passou por inúmeras mutações que conferiu a estes, a habilidade em ocasionar infecções graves tanto também nas vias respiratórias inferiores.

Contudo, existem inúmeros tipos de Coronavírus descritos atualmente, responsáveis por causar doenças respiratórias em mamíferos, assim como, nos seres humano. Os primeiros Coronavírus causadores de patologias humanas foram descobertos ainda no ano de 1937 (Oliveira, 2020). De acordo com Peiris et al., (2003), a primeira epidemia ocasionada por um vírus da família Coronaviridae ocorreu ainda no século XXI, em que foi descoberto que um novo agente patogênico viral (denominado SARS- Cov) que era o responsável por causar doenças respiratórias em animais também estava contaminando seres humanos na população de Hong Kong na China (Souza et al., 2021).

Este vírus apresentava grandes habilidades de disseminação e infecção, espalhando-se rapidamente em toda a província chinesa, com projeção para todos os continentes do mundo (Zhong et al., 2003). O SARS- Cov, apresentou um total de 8.000 infectados e uma taxa de óbitos 9,6\%, com um total de 774 indivíduos vítima fatal da doença pulmonar, com evolução para pneumonia atípica ocasionada por este vírus (Souza et al., 2021). Em menos de 1 ano em que se iniciou esta epidemia, a mesma foi controlada e, ressurgiu em 2004 que novamente foi controlada (Who, 2004), evitando assim, uma nova disseminação global. 
Em 2012, uma nova epidemia também ocasionada por um novo Coronavírus de origem zoonótica (provavelmente o patógeno tem o camelo com hospedeiro permanente), levou a ocorrência de uma nova doença respiratória que se originou na população do Oriente Médio (Arábia Saudita). Esta foi então conhecida como MERS- Cov (Síndrome Respiratória do Oriente Médio), com uma alta taxa de infecção e mortalidade (34,4\% dos infectados morreram em decorrência de complicações com a doença) (Souza et al., 2021).

Em um espaço de tempo relativamente curto, esta doença alcançou outras localidades do mundo, como por exemplo, o continente Asiático, onde foi registrado o maior número de casos. Posteriormente, o vírus alcançou a Europa, a África e a América no ano de 2014. Até o ano de 2019, esta doença já tinha contaminado um total de 2.494 pessoas, com 858 que evoluíram para óbito em todo o mundo (Brasil, 2014).

Já em dezembro de 2019, na cidade Wuhan na China foi registrado um elevado número de internações de pacientes com um quadro grave de uma desconhecida síndrome respiratória aguda que se disseminou rapidamente por entre a população e, causou pânico devido a velocidade de evolução da doença, que em um espaço curto de tempo levou inúmeros pacientes a óbito. Ainda ano de 2019, o agente causador desta doença foi identificado (confirmado por meio de biologia molecular em 2020) e, para surpresa dos pesquisadores, mais uma vez um representante da família Coronaviridae foi o responsável por ocasionar uma doença respiratória grave.

Este agente foi então denominado Sars- Cov -2, um novo Coronavírus que foi descrito no final de 2019, na China, causando um quadro patológico chamado de Covid-19 (Lima, 2020), sendo então, o responsável pela maior pandemia do século XXI (Yee et al., 2020 \& Lana et al., 2020).

O primeiro caso confirmado de COVID-19 no Brasil ocorreu em 22 de janeiro de 2020. Posterior a confirmação da presença do patógeno em um paciente brasileiro, este se disseminou rapidamente e em progressão geométrica, levando o brasileiro a adotar medidas de prevenção da doença como aqueles preconizados pela Organização Mundial de Saúde e previamente adotadas em outros países, como por exemplo, o isolamento social (Neto et al., 2020).

A COVID-19 é uma doença que gera sintomas indefinidos, os quais são distintos a depender do quadro em que o paciente afetado se encontra, tendo em vista que pessoas com comorbidades pré-existentes ou doenças autoimunes são as que apresentam sintomas mais graves, que podem levar a morte. Porém, mesmo este agente patogênico sendo o representante da família Coronaviridae que até então apresenta maior habilidade de infecção a nível global, este, possui uma taxa de mortalidade em torno de 3,4\%, sendo consideravelmente menor em comparação aos demais (Duarte, Quintana, 2020 \& Lana et al., 2020).

Os sintomas clínicos da infecção por Sars-Cov-2 são amplos, podendo variar de um simples resfriado até uma grave pneumonia. Os principais sintomas são: febre persistente, perda do olfato, perda do paladar, dores de garganta, tosse, dispneia, cefaleia e diarreia.

O diagnóstico da doença é possível por meio de dois tipos principais de exames, os quais são conhecidos como RTPCR (identificação molecular do agente causador da doença), que é realizado até o quinto dia de infecção, através da coleta de material biológico retirado da nasofaringe do paciente com o auxílio de um Swab e encaminhado para análise em laboratório. Já o segundo teste, é o sorológico em que serão identificados a existência de células de defesa ou de memória para o vírus por meio de um teste rápido para COVID-19, o qual é realizado apenas após o oitavo dia de infecção e/ou o teste quantitativo, ao qual envolve a coleta e a análise do sangue do paciente (Lima, 2020).

O contágio ocorre preferencialmente através do contato ou proximidade com uma pessoa doente, por meio de ações que envolvem aperto de mão, abraços, contato direto ou indireto com aerossóis (gotas de saliva, espirros e/ou tosse), assim como, pelo contato direto com superfícies contaminadas (Oliveira, 2020 \& Neto et al., 2020). O vírus adentra o organismo do hospedeiro preferencialmente através das vias respiratórias superiores, ao entrar em contato com o ar contaminado, ou, ao levar a mãos contaminada diretamente na boca, nos olhos ou nariz. O período de incubação do vírus é variado, no entanto, pode levar de 2 a 
14 dias após o primeiro contato com o patógeno, geralmente vem acompanhada de comuns como febre, tosse e dificuldade leve para respirar (Oliveira, 2020 \& Brasil, 2020).

A prevenção da doença só é possível por meio do distanciamento social, evitando eventos de aglomeração, pois, ainda não foi descoberto um tratamento medicamentoso para combater a replicação do vírus no organismo do hospedeiro. Outra indicação preventiva da doença é, o uso obrigatório de máscaras faciais cirúrgicas de ampla proteção, assim como, os cuidados para a higienização das mãos, especialmente com água e sabão ou, álcool 70\%, pois, este é capaz de destruir a estrutura viral do patógeno, evitando então a sua disseminação.

O isolamento social é uma medida preventiva, que tem por finalidade conter a propagação da doença e as inúmeras mortes geradas por ela. Os especialistas recomendam o confinamento em casa, e a Organização Mundial da Saúde recomenda a toda população que é de suma importância a prevenção, assim como, usar máscaras, manter o distanciamento, usar álcool 70\% e lavagem das mãos (Orso, 2020).

Devido as condições para a prevenção da doença, o novo Coronavírus gerou mudanças drásticas na sociedade mundial, inclusive dos brasileiros, afetando não somente a saúde pulmonar da população, mas também, a saúde mental, devido os eventos de isolamento social.

\section{Mídias sociais e COVID-19: Impactos das Fake News na saúde mental da população}

As mídias de comunicação sociais atualmente representam um excelente canal para disseminação de informações sobre temas variados e de relevância comunitária. Atualmente, estas mídias estão sendo altamente exploradas, especialmente para a divulgação de conteúdos sobre saúde e educação, com a finalidade de informar a sociedade sobre aspectos importantes referentes a pandemia da COVID-19.

Portanto, o isolamento social como fator de contenção da disseminação do novo Coronavírus tornou as mídias sociais uma forte ferramenta para a educação em saúde, sendo considerada uma das maiores fontes de propagação de orientações acerca da doença, especialmente sobre prevenção e as contínuas descobertas relacionadas a ela.

Assim, através das mídias sociais são compartilhadas medidas de prevenção e tratamento da sintomatologia da doença, orientações sobre o que um indivíduo precisa fazer ao ter contato com pessoas infectadas por Coronavírus. Com a finalidade de maximizar as possibilidades de um diagnóstico precoce, as mídias sociais também permitem a realização de consultas virtuais, assim como, a criação de aplicativos que buscassem promover a informatização da população (Silva et al., 2020).

Diante desta perspectiva, de acordo com Silva et al., (2020), a educação em saúde envolve ações que servem para orientar a população com relação as boas práticas de saúde com responsabilidade, por meio de diferentes categorias de forma intersetorial e interprofissional, com a finalidade de aprimorar a qualidade dos serviços prestados à população. Contudo, todas as informações partilhadas são realizadas com o enfoque principal na promoção e prevenção em saúde, visto que com o distanciamento, a melhor ferramenta para que as orientações chegassem até a população, foi a criação de aplicativos e compartilhamento de sites de informatizações da saúde, assim como, publicações em redes sociais de grande impacto.

No entanto, na contramão das orientações prestadas para promoção da saúde por profissionais capacitados e por meio das mídias, Fakes News também foram geradas. Falsas informações foram propagadas por diferentes protagonistas em uma diversidade de formas, ocasionando um caos na saúde, pois, o senso comum passou a crer e compartilhar estas falsas informações, desqualificando e contrapondo informações científicas com a finalidade de minimizar a doença e os impactos causados pela pandemia (Júnior et al., 2020 \& Neto et al., 2020).

De acordo com Neto et al., (2020), Fake News são classificadas como notícias e/ou informações sem veracidade comprovada que tem por finalidade fornecer falsas informações ao leitor com intensão de causar rumores, desinformação e manipulação das informações com intensões duvidosas (Garcia \& Duarte, 2020). Esta ação consta na literatura desde o antigo 
Império Romano, no entanto, na atualidade as consequências geradas por Fake News são incalculáveis devido a velocidade ao qual são disseminadas por meio da internet (Allcott \& Gentzkow, 2017).

Em território brasileiro, a disseminação de notícias com teor falso e com objetivo de manipulação da situação é bastante intensa. De acordo com a Fiocruz (2020), as Fake News sobre a pandemia são divulgadas principalmente via WhatsApp, Facebook e Instagram. Ainda de acordo com este autor, uma das maiores Fake News divulgadas através destas redes sociais está relacionada a falsa informação da não existência de casos de COVID-19 no Brasil, sendo anexada a estas informações imagens de leitos de hospital desocupados.

Também foram disseminadas inúmeras notícias com teor de métodos caseiros sem comprovação cientifica de sua eficácia para a prevenção e/ou tratamento da COVID-19, assim como, teorias da conspiração associando a pandemia a questões políticas que favoreciam o negacionismo e aguçava opiniões e ações que contradiziam as medidas de distanciamento social preconizados pela Organização Mundial da Saúde para a contenção da propagação do vírus (Fiocruz, 2020).

De acordo com Brooks et al., (2020), neste período de enfrentamento a disseminação e contaminação pela COVID-19 é notório o adoecimento mental da população (Zandifar \& Badrfam, 2020). Durante a expansão da pandemia pelo globo terrestre, foram identificados a prevalência de Transtornos Mentais Comuns (TMC) na população de forma geral, tais como: ações e reações agressivas, sensação de fadiga, aumento na taxa de estresse de forma aguda, episódios de pânico, eventos de depressão e ansiedade (Cruz et al., 2020).

Alguns estudos sugerem ainda que, estes transtornos mentais podem estar intimamente ligados ao volume de notícias (infodemia) e informações veiculadas pelas mídias sociais sobre o avanço e descontrole da doença, especialmente, aquelas relacionadas a mitos e mentiras provocando pânico por entre as pessoas (Chen et al., 2020; Bao et al., 2020; Goyal et al., 2020; Barros-Delben et al., 2020 \& Shimizu, 2020), assim como, a não existência de um tratamento, o elevado número de contaminação e de óbitos, dentre outros.

Porém, a propagação de informações através das mídias durante a pandemia do novo Coronavírus proporcionou destaque para os profissionais da enfermagem, os quais partilharam mensagens, relatos de experiências diárias ao lidarem com o sofrimento de pacientes e familiares afetados pela doença. Toda a classe de enfermagem trabalha na linha de frente de combate ao COVID-19, os quais estão desde a admissão do paciente ao recebimento da alta por cura ou melhora. Estes profissionais utilizam do conhecimento científico e das mídias com a finalidade de alertar a população, a fim de, demonstrar a real importância da prevenção à doença (Domingues et al., 2020).

\section{Saúde mental em tempos de pandemia}

A saúde mental em tempos de pandemia na maioria das vezes é negligenciada, tendo em vista que a prioridade dos profissionais da saúde e dos cientistas é o controle da doença ou até mesmo a busca por uma cura, por uma forma eficaz de preveni-la. Segundo algumas pesquisas realizadas, pode-se observar que o surto por COVID-19 além de gerar alterações físicas, afetou drasticamente o bem-estar psicológico da população, pois foram gerados medo e pânico, problemas os quais puderam acarretar distúrbios psiquiátricos (Lima et al., 2020).

Diante do exposto por Nabuco et al., (2020), observa-se que os impactos ocasionados pelo período pandêmico podem afetar o bem-estar psicossocial da população, de tal modo, que pode gerar o adoecimento mental tanto de pessoas sem doenças subjacentes quanto de quem possui doença mental pré-existente, e mesmo que não haja exposição de uma pessoa à infecção, o medo, ansiedade, insegurança, estresse, desamparo, tristeza e o sentimento de incapacidade podem afetar a saúde mental do indivíduo.

De acordo com Lima et al., (2020), as condições geradas pelo COVID-19 são fatores estressores que são suficientes para gerar traumas psicológicos em toda a sociedade, e isto, por sua vez, tem sido comprovado cada vez mais mediante pesquisas, 
as quais apontam que a grande maioria da população tem sofrido, psicologicamente, devido aos fatores de distanciamento e de risco de contaminação. E diante da pesquisa apresentada, pode-se observar um aumento ponderal de admissão de pacientes que necessitam de psiquiatria, onde boa parte apresenta comportamentos que são perigosos até mesmo para os profissionais, como a destruição dos Equipamentos de Proteção Individual (EPIs).

O surto por COVID-19 tem sido considerado um dos maiores problemas de saúde pública nas últimas décadas, tendo em vista que atinge as pessoas em diferentes níveis de complexidade, de forma grave e até letal, onde cada organismo tende a reagir de uma forma diferente diante da infecção pelo vírus (Faro et al., 2020). Assim, Nabuco et al., (2020), afirma em sua pesquisa que as limitações expostas pelo isolamento físico e a quarentena são sem dúvida um dos fatores estressores que impactam a todos, principalmente, idosos e crianças. Aponta ainda, que a duração prolongada dessas medidas afeta a saúde mental dos indivíduos de maneira que possa levar ao adoecimento.

De acordo com Raiol (2020), a prevenção dos distúrbios mentais e o aumento do sistema imunológico pode ser realizado através da prática de exercícios físicos. No entanto, devido ao isolamento social e o distanciamento, grande parte da população tem deixado de realizar atividades físicas, mesmo aquelas as quais podem ser realizadas em casa, e isto devido à falta de estrutura apropriada. O autor ressalta, também, que a atividade física tem sido sugerida a população com base na diminuição do estresse e da ansiedade gerada pelo isolamento.

Diante disso, Faro et al., (2020) afirma que existem três momentos durante uma crise, são: pré-crise, intracrise e póscrise, e em cada um destes momentos é possível observar maiores repercussões na saúde mental. Assim, no momento pré-crise ocorre o repasse de informações sobre a doença, momento no qual pode ser desencadeado emoções negativas, medo, tristeza e angústia; o momento intracrise é quando o problema está na fase aguda, onde pode-se notar a gravidade e a vulnerabilidade ao adoecimento, e neste, há potencial de impacto severo na saúde mental da população; o momento pós-crise é quando há a reconstrução social, quando ocorre o declínio de casos da doença e a possibilidade de restauração do estado de saúde.

\section{Impactos dos eventos de isolamento social para a saúde mental de acadêmicos do Brasil}

O isolamento social devido a pandemia da COVID-19 é considerado um dos fatores de maior impacto na saúde mental do brasileiro, especialmente, na população de acadêmicos. Estes impactos podem estar relacionados aos vários eventos de ansiedade e depressão desenvolvidos por estes estudantes durante o seu período de distanciamento social.

De acordo com a pesquisa desenvolvida por Schuchmann et al., (2020), enfatiza que, há uma certa diferença entre isolamento social e quarentena, onde o isolamento consiste na separação de pessoas contaminadas das não contaminadas. Já a quarentena significa manter-se em restrição de atividades e a segregação de pessoas que podem ou não estar contaminadas, as quais poderiam ter entrado em contato com a infecção de maneira indireta.

De acordo com Pereira et al., (2020), o isolamento social foi designado como uma das medidas preventivas de enfrentamento ao COVID-19, tendo em vista que a doença pode ser transmitida de pessoa a pessoa por gotículas de saliva, espirro, tosse, entre outras, sendo assim, necessário manter no mínimo um metro e meio de distância entre um indivíduo e outro. Ainda de acordo com este autor, além do distanciamento entre os indivíduos, houve a proibição de qualquer tipo de aglomeração, visando a redução do número de casos da doença.

Em algumas regiões do Brasil, foi possível observar o quantitativo de pessoas que obedeciam ao período de isolamento. Estes cálculos foram realizados através do Índice de Isolamento Social (IIS) elaborado e gerido pela empresa Inloco. Esta empresa é uma startup no ramo da tecnologia, ao qual tem acompanhado a movimentação de mais de 60 milhões de brasileiros através da localização dos smartphones dos indivíduos (Natividade et al., 2020).

Por conseguinte, algumas pesquisas apontam que o período de quarentena em consonância com o distanciamento social gerou inúmeras consequências para a saúde mental da população, tendo em vista a necessidade de adaptação e a desinformação 
sobre a doença, o que levou inúmero indivíduos a morte (Lima, 2020). Assim, segundo Lima (2020), foi produzida uma situação de estresse e medo por entre a população, ocasionando inúmeros distúrbios psicológicos e psiquiátricos, como a sensação de impotência, solidão, irritabilidade e tristeza.

De acordo com Rodrigues et al., (2020), na China, durante o início do surto de COVID-19, um inquérito apontou a ansiedade de forma grave em um terço dos indivíduos, isto tem sido observado também na população brasileira, tendo em vista a situação pandêmica que ocasionou o fechamento de escolas, faculdades, institutos e universidades, afetando drasticamente um grande número de acadêmicos. Neste sentido, algumas pesquisas demonstram que, a maioria da população possui estresse póstraumático e insônia em decorrência da pandemia (Bezerra et al., 2020).

Estes impactos estão relacionados aos eventos de isolamento social, pois, abruptamente estas pessoas foram obrigadas a deixas os bancos das salas de aula e ocupar o espaço limitante de suas residências. Segundo Coelho et al., (2020), os impactos ocasionados nos estudantes estão relacionados especialmente, ao afastamento destas pessoas de suas atividades acadêmicas de forma presencial, assim como, da convivência cotidiana com os colegas de aula, professores e comunidade interna e externa a universidade e/ou faculdade, ao qual interagiam fortemente durante a execução de projetos de extensão, as pesquisas universitárias, especialmente, as pesquisas de campo, os estágios etc.

De acordo com relatos de Trópia et al., (2019), os estudantes universitários representam uma das classes mais sensível ao distanciamento físico e a privação da convivência social, pois, o maior número de estudantes encontram-se na fase transição entre a adolescência e a juventude, onde ocorrem inúmeras alterações comportamentais do indivíduo. Segundo Blakemore \& Mills (2014), “a adolescência, particularmente, representa um período delicado para o desenvolvimento, e a interação social é fundamental nesta fase".

Portanto, para os estudantes fatores como: o medo e a ansiedade envolvendo questões de sobrevivência relacionados a desemprego, riscos de contaminação, isolamento, solidão, privação e outros, podem afetar drasticamente a saúde mental destas pessoas, pressionando-os a mudanças obrigatórias em seus estilos de vida (Coelho et al., 2020).

Neste sentido, Ribeiro et al., (2020), esclarece que “o isolamento/afastamento social potencializa ainda mais a utilização dos meios tecnológicos, certamente um agravante de vários fatores psicológicos”. Portanto, a necessidade da utilização de recursos tecnológicos para o acompanhamento das aulas online em substituição desta prática de forma presencial, assim como, as mudanças na rotina de estudos gerida pelo próprio estudante também influenciam nas questões da saúde mental destas pessoas.

De acordo com Hall (1998), o isolamento social não afeta somente as questões que envolvem a saúde mental do indivíduo, mas também, pode levar a serias consequências no funcionamento cognitivo destes, pois, os eventos de privação do contato presencial com outras pessoas podem reduzir a intensidade de estímulos cerebrais fundamentais para o seu desenvolvimento.

Portanto, os inúmeros desafios propostos e associados ao enfrentamento da pandemia estão cada vez mais sendo reavaliados, especialmente, quando relacionados aos impactos gerados na saúde mental, visto que produzem alterações emocionais, cognitivas e comportamentais entre a maioria dos indivíduos, considerando que, saúde mental não é apenas a ausência de transtornos, mas sim, a promoção do bem estar físico e mental, levando a buscar mais conhecimentos acerca do enfrentamento do estresse e o controle das emoções por estas pessoas (Emuno et al., 2020).

\section{Considerações Finais}

Diante do exposto foi possível concluir que, a pandemia de COVID-19 acarretou uma variedade de problemas sociais em populações de todo o globo terrestre, inclusive, no Brasil. Problemas relacionados ao distanciamento social que vão além da 
gravidade da doença e, abrange setores econômicos, políticos e estruturais. No entanto, a maior consequência devida da pandemia está relacionada a saúde do indivíduo, especialmente a saúde mental devido os eventos de isolamento social.

De forma geral, foi possível observar que, os principais problemas de saúde mental que estão associados aos eventos de isolamento são: depressão, ansiedade, insônia, estresse, irritação, medo, angústia, dentre outras e, atingem o brasileiro de norte a sul do país. No entanto, um dos públicos de maior sensibilidade as mudanças impostas pela pandemia são os estudantes universitários, pois, a maioria se encontra na fase de transição entre a adolescência e a juventude, momento este que, demanda bastante da proximidade e relações sociais.

Desta forma, uma das supostas soluções para este problema seria a disponibilidade de psicólogos e psiquiatras gratuitos em programas de atendimento online, podendo este projeto, ser fomentado pelo poder público ou até mesmo pela instituição de ensino superior ao qual o acadêmico encontra-se matriculado. Outro ponto importante que poderia ser praticado, seriam estágios e/ou projetos de extensão realizados por acadêmicos e professores na área da saúde, com o instituto de triar e trabalhar um suposto adoecimento mental de acadêmicos de outras áreas, implantando projetos de atendimento online destes alunos, a fim de, tratar o transtorno antes que ele possa se agravar.

\section{Referências}

Allcott, H., \& Gentzkow, M. (2017). Social media and Fake News in the 2016 election. Journal of Economic Perspectives, 31, 211-236.

Bao, Y., Sun, Y., Meng, S., Shi, J., \& Lu, L. (2020). 2019-nCoV epidemic: Address mental health care to empower society. The Lancet, 395 , e37-e38.

Barros-Delben, P., Cruz, R. M., Trevisan, K. R. R., Gai, M. J. P., Carvalho, R. V. C., Carlotto, R. A. C., \& Malloy-Diniz, L. F. (2020). Saúde mental em situação de emergência: COVID-19. Revista Debates in Psychiatry, 10.

Bezerra, A. C. V., Silva, C. E. M., Soares, F. R. G., \& Silva, J. A. M. (2020). Fatores associados ao comportamento da população durante o isolamento social na pandemia de COVID-19. Creative Commons, 2411-2421.

Blakemore, S. J., \& Mills, K. L. (2014). Is adolescence a sensitive period for sociocultural processing? Annual Review of Psychology, 65: 187-207.

Brasil. (2020). Ministério da Saúde (BR). Secretaria de Vigilância em Saúde. Coronavírus: Covid-19. 2020. Disponível em: 〈https://coronavirus.saude.gov.br/>. Acesso em: 08 jun. 2021.

Brasil. (2014). Ministério da Saúde. MS. Informe Técnico - MERS-CoV (Novo Coronavírus). <Informe Técnico para Profissionais da Saúde sobre MERSCoV_09 062014 (saude.gov.br)>.

Brasil. (2020). Ministério da Saúde. Covid-19. 2020. <https://coronavirus.saude.gov.br/>.

Brooks, S. K., Webster, R. K., Smith, L. E., Woodland, L., Wessely, S., Greenberg, N., \& Rubin, G. J. (2020). The psychological impact of quarantine and how to reduce it: rapid review of the evidence. The Lancet. 20: 30460-8.

Chen, Q., Liang, M., Li, Y., Guo, J., Fei, D., Wang, L., \& Zhang, Z. (2020). Mental health care for medical staff in China during the COVID-19 outbreak. The Lancet Psychiatry, 7, 15-16.

Coelho, A. P. S., Oliveira, D. S., Fernandes, E. T. B. S., Santos, A. L. De S., Rios, M. O., Fernandes, E. S. F., Novaes, C. P., Pereira, T. B., \& Fernandes, T. S. S. (2020). Saúde mental e qualidade do sono entre estudantes universitários em tempos de pandemia da COVID-19: experiência de um programa de assistência estudantil. Research, Society and Development, 9, e943998074.

Cruz, R. M., Borges-Andrade, J. E., Moscon, D. C. B., Micheletto, M. R. D., Esteves, G. G. L., Delben, P. B., Queiroga, F., \& Carlotto, P. A. C. (2020). Covid19: Emergência e Impactos na Saúde e no Trabalho. Revista Psicologia: Organizações e Trabalho, 20, 1-3.

Duarte, G., \& Quintana, S. M. (2020). Infecção pelo Coronavírus SARS-CoV-2 em Obstetrícia: Enfrentando o desconhecido. < https://www.sogesp.com.br/noticias/infeccao-pelo-coronavirus-sars-cov-2-em-obstetricia-enfrentando-o-desconhecido/>.

Emuno, S. R. F., Weide, J. N., Vincentini, E. C. C., Araujo, M. F., \& Machado, W. L. (2020). Enfrentando o estresse em tempos de pandemia: proposição de uma Cartilha. Rev. Estudo de Psicologia, 37, 1-10.

Murakami, K., Panúncio-Pinto, M. P., Santos, J. L. F. Dos, \& Troncon, L. E. de A. (2019). Estresse psicológico em estudantes de cursos de graduação da área da saúde: subsídios para promoção de saúde mental. Rev. Med., 108- 113.

Faro, A., Bahiano, M. A., Nakano, T. C., Reis, C., Silva, B. F. P., \& Vitti, L. S. (2020). Covid-19 e saúde mental: a emergência do cuidado. Scielo, 37.

Fiocruz. (2020). Fundação Oswaldo Cruz. Estudo identifica principais fake news relacionadas à Covid-19. Fiocruz, $2020<$ https://portal.fiocruz.br/noticia/estudo-identifica-principais-fake-news-relacionadas-covid-19>. 
Garcia, L. P., \& Duarte, L. (2020). Infodemia: excesso de quantidade em detrimento da qualidade das informações sobre a COVID-19. Epidemiol. Serv. Saude, Brasília, 29, e2020186, 2020.

Gil, A. C. (1999). Métodos e técnicas de pesquisa social. (5a ed.), Atlas

Gil, A. C. (2006). Como elaborar projetos de pesquisa. (4a ed.), Atlas

Goyal, K., Chauhan, P., Chhikara, K., Gupta, P., \& Singh, M. P. (2020). Fear of COVID 2019: First suicidal case in India. Rev. Asian Journal of Psychiatry, 49: 101989.

Hall, F. S. (1998). Social deprivation of neonatal, adolescent, and adult rats has distinct neurochemical and behavioral consequences. Critical Reviews in Neurobiology. 12: 129-62.

Homma, A., Martins, R. M., Leal, M. L. F., Freire, M. S. \& Couto, A. R. (2011). Atualização em vacinas, imunizações e inovação tecnológica. Rev. Ciência \& Saúde Coletiva, 16, 445-458.

Júnior, L. A. S. (2020). Pandemias. Revista da FAESF, 4: 79-83.

Lakatos, E. M., \& Marconi, M. A. (2003). Fundamentos da metodologia científica. (5a ed.), Atlas.

Lakatos, E. M., \& Marconi, M. A. (2002). Técnicas de pesquisa: planejamento e execução de pesquisas. (5a ed.), Atlas.

Lakatos, E. M., \& Marconi, M. A. (2010). Fundamentos de Metodologia Científica. (7a ed.), Atlas.

Lana, R. M., Coelho, F. C., Gomes, M. F. D. C., Cruz, O. G., Bastos, L. S., Villela, D. A. M., \& Codeço, C. T. (2020). Emergência do novo coronavírus (SARSCoV-2) e o papel de uma vigilância nacional em saúde oportuna e efetiva. Cad. Saúde Pública, 36

Leal, M. G. F., \& Lima, F. R. (2009). Metodologia da pesquisa: Módulo VI, Curso de Especialização em Educação Tecnológica. CEFET/RJ. Rio de Janeiro. Lima, R.C. (2020). Distanciamento e isolamento sociais pela Covid-19 no Brasil: impactos na saúde mental. Revista de Saúde Coletiva, 30, 1-10.

Lima, S. O., Silva, M. A., Santos, M. L. D., Moura, A. M. M., Sales, L. G. D., Menezes, L. H. S., Nascimento, G. H. D., Oliveira, C. C. C., Reis, F. P., \& Jesus, C. V. F. (2020). Impactos no comportamento e na saúde mental de grupos vulneráveis em época de enfrentamento da infecção COVID-19: revisão narrativa. Rev. Eletrônica Acervo Saúde, 46: 1-8.

Martins, M. M., Jungues, F., Cantão, P. C., Brittes, A. H. C., \& Machado, J. N. (2016). Epidemias mundiais: um histórico sobre as principais doenças com potencial emergente. Salão de pós-graduação, 8

Monari, A. C. P., \& Bertolli Filho, C. (2019). Saúde sem Fake News: estudo e caracterização das informações falsas divulgadas no canal de informação e checagem de Fake News do ministério da saúde. Revista Mídia e Cotidiano, 13, 160-186.

Murakami, K., Panuncio-Pinto, M. P., Santos, J. L. F., Trocon, L. E. A. Nabuco, G., Oliveira, M. H. P. P., \& Afonso, M. P. D. (2020). O impacto da pandemia pela COVID-19 na saúde mental: qual é o papel da Atenção Primária à Saúde? Rev. Bras. de Med. da Família e Comunidade, $15,1-11$.

Natividade, M. S., Bernades, K., Pereira, M., Miranda, S. S., Bertoldo, J., Teixeira, M. G., Livramento, H. L., \& Aragão, E. (2020). Distanciamento social e condições de vida na pandemia COVID-19 em Salvador-Bahia, Brasil. Rev. Ciência \& Saúde Coletiva, 25, 3385-3392.

Neto, M., Gomes, T. De O., Porto, F. R., Rafael, R. De M. R., Fonseca, M. H. S., \& Nascimento, J. (2020). Fake news no cenário da pandemia de Covid-19. Cogitare enferm, 25: e72627.

Oliveira, E. H. A. (2020). Coronavírus: prospecção científica e tecnológica dos fármacos em estudo para tratamento da Covid-19. Cadernos de Prospecção -13, 412-423.

Ornell, F., Schuch, J. B., Sordi, A. O., \& Kessler, F. H. P. (2020). Pandemia de medo e Covid-19: impacto na saúde mental e possíveis estratégias. Rev. Debates in Psychiatry, 2-7.

Pereira, A.S., et al. (2018). Metodologia da pesquisa científica. UFSM.

Pereira, M. D., Oliveira, L. C., Costa, C. F. T., Bezerra, C. M. O., \& Pereira, M. D. (2020). A pandemia de COVID-19, o isolamento social, consequências na saúde mental e estratégias de enfrentamento: uma revisão integrativa. Research, Society and Development, 9, 1-31.

Raiol, R. A. (2020). Praticar exercícios físicos é fundamental para a saúde física e mental durante a Pandemia da COVID-19. Brazilian Journal of health Review, $3,2804-2813$

Ribeiro, A. C. R. C., Marques, M. C. C., \& Mota, A. (2020). A gripe espanhola pela lente da história local: arquivos, memória e mitos de origem em Botucatu, SP, Brasil, 1918. Rev. Interface Comunicação, Saúde, Educação, 1-16.

Ribeiro, E. (2008). A perspectiva da entrevista na investigação qualitativa. Rev. Evidência, olhares e pesquisas em saberes educacionais, 4: 129-148.

Ribeiro, E. G., Souza E. L., Nogueira J. O., \& Eler R. (2020). Saúde Mental na Perspectiva do Enfrentamento à COVID -19: Manejo das Consequências Relacionadas ao Isolamento Social. Rev. Enfer. e saúde coletiva, 5, 47-57.

Rodrigues, B. B., Cardoso, R. R. J., Peres, C. H. R., \& Marques, F. F. (2020). Aprendendo com o Imprevisível: Saúde Mental dos Universitários e Educação Médica na Pandemia de Covid-19. Rev. Bra. de Ed. Medica, 44 e0149.

Schmidt, B., Crepald, M. A., Bolze, S. D. A., Silva, L. N., \& Demenech, L. M. (2020). Saúde mental e intervenções psicológicas diante da pandemia do novo coronavírus (COVID-19). Rev. Estudos de Psicologia, 37: 1-13. 
Research, Society and Development, v. 10, n. 9, e3410917385, 2021

(CC BY 4.0) | ISSN 2525-3409 | DOI: http://dx.doi.org/10.33448/rsd-v10i9.17385

Schuchmann, A. Z., Schnorrenberger, B. L., Chiquetti, M. E., Gaiki, R. S., Raimann, B. W., \& Maeyama, M. A. (2020). Isolamento social vertical X Isolamento social horizontal: os dilemas sanitários e sociais no enfrentamento da pandemia de COVID-19. Rev. Brazilian Journal of health Review, 3 , $3556-3576$.

Shimizu, K. (2020). 2019-nCoV, fake news, and racism. Rev. The Lancet, 395, 685-686.

Silva, A. F., Estrela, F. M., Lima, N. S., \& Abreu, C. T. A. (2020). Saúde mental de docentes universitários em tempos de pandemia. Rev. de Saúde Coletiva, 30: $1-4$.

Silva, E. L., \& Menezes, E. M. (2005). Metodologia da pesquisa e elaboração de dissertação. (4a ed.), rev. atual. UFSC, 138p.

Siqueira, M. A. S. (2013). Monografias e teses: das normas técnicas ao projeto de pesquisa. (2a ed.), Consulex.

Souza, A. S. R., Amorim, M. M. R., Melo, A.S.O., Delgado, A. M., Florêncio, A. C. M. C.C., Oliveira, T. V., Lira, L. C. S., Sales, L. M.S., Souza, G. A., Melo, B. C. P., Morais, I., \& Katz, L. (2021). Aspectos gerais da pandemia de COVID-19. Rev. Bras. Saúde Matern. Infant., 21 S47-S64.

Souza, L. C., Silva, T. O., Pinheiro, A. R.S., \& Santos, F. S. (2021). SARS-CoV, MERS-CoV e SARS-CoV-2: uma revisão narrativa dos principais Coronavírus do século. Rev. Brazilian Journal of Health Review, 4, 1419-1439.

Trópia, V. P., Silva, M. A. S., Mathias F. R., Maia, A. S., Gomes, D. C., Souza, D. C., Feres J. J., Belisário, F., Soares, J., Ferreira, A. L., Reis F. M. G., Batista, L. G. R., \& Lima, S, S. (2019). V Pesquisa Nacional de Perfil Socioeconômico e Cultural dos (as) Graduandos (as) das IFES. 2019. http://www.fonaprace.andifes.org.br/site/wp-content/uploads/2019/06/V-Pesquisa-do-Perfil-Socioecono\%CC\%82mico-dos-Estudantes-de-

Graduac\%CC\%A7a\%CC\%83o-das-U.pdf>.

Venceslau, K. F. R., Abreu, K. D., Andrade, S. P., Carvalho, A. V., Rodrigues, F. A., \& Guimarães, A.P.M. (2017). Tuberculose respiratória: histórico, atualização do diagnóstico e dificuldades do tratamento. Rev. Scire Salutis, 7, 38-52.

Wang, L., Wang, Y., Ye, D., \& Liu, Q. (2020). Review of the 2019 novel coronavirus (SARS-CoV-2) based on current evidence. Int J Antimicrob Agents. n. 55: p.105948.

Yee, J., Unger, L., Zadravecz, F., Cariello, P., Seibert, A., Johnson, M. A., \& Fuller, M. J. (2020) Novel coronavirus 2019 (COVID-19): Emergence and implications for emergency care. Jacep Open, 1, 7.

Zandifar, A., \& Badrfam, R. (2020). Iranian mental health during the COVID-19 epidemic. Asian Journal of Psychiatry, 51 : 101990. 